\title{
Alien Shakespeares 2.0
}

\section{Christy Desmet}

\section{(2) OpenEdition \\ Journals}

Electronic version

URL: http://journals.openedition.org/shakespeare/3877

DOI: 10.4000/shakespeare.3877

ISSN: 2271-6424

\section{Publisher}

Société Française Shakespeare

\section{Electronic reference}

Christy Desmet, "Alien Shakespeares 2.0 ", Actes des congrès de la Société française Shakespeare [Online], 35 | 2017, Online since 01 February 2017, connection on 01 May 2019. URL : http:// journals.openedition.org/shakespeare/3877 ; DOI : 10.4000/shakespeare.3877

This text was automatically generated on 1 May 2019.

(c) SFS 


\title{
Alien Shakespeares 2.0
}

\author{
Christy Desmet
}

1 "Shakespeare," under the sign of Web 2.0, has remained a divided field or doubled object of interpretation. New Media Shakespeares, of which YouTube is the most popular example, tend to be brief, quixotic, and lacking in high seriousness. We need look no further than the recent spate of Hamlet school parodies, of varying poetic and narratological merits, which set the plot of Shakespeare's tragedy to Miley Cyrus's song "Wrecking Ball." Digital Humanities approaches to the Shakespearean text, as exemplified by textual corpora and authorship studies, work on a grand scale and are marked by methodological rigor. Emphasizing the material differences between these two kinds of digital work, however, obscures similarities that could let us see digitized Shakespeares of different kinds as co-existing along a continuum. In this essay, I suggest a possible rapprochement between these divided disciplinary siblings, New Media and Digital Humanities Shakespeare, through Ian Bogost's concept of "alien phenomenology"; I argue that Bogost's theoretical framework provides a way to understand digital objects as disaggregated "configurations" of "units" and "systems" - these are Bogost's terms that have an individuated integrity while also engaging in shifting relationships with other units. ${ }^{2}$ Through Bogost's articulation of alien phenomenology, we can see a kinship linking such apparently unrelated objects as a YouTube video featuring LEGO versions of Romeo and Juliet, the digitized facsimile of a page from the first quarto Hamlet with marginalia, and the results of a word search in the Folger Digital Texts.

\section{Alien Phenomenology and Tiny Ontology}

2 Alien Phenomenology traces its genealogy to two strands in contemporary thought: first, the reconfiguration of human-machine relations that runs from Donna Haraway's vision of the cyborg through N. Katherine Hayles's definition of the posthuman; and second, the reconfiguration of human-object relations epitomized by Jane Bennett's vital materialism and other versions of Object Oriented Ontology (000). ${ }^{3}$ Both contribute to the project of dismantling the old liberal humanist subject, first discussed in Shakespeare studies by materialist writers, through new articulations of subject-object relations. Catherine 
Belsey, for instance, writes in 1985 that "liberal humanism proposes that the subject is the free, unconstrained author of meaning and action, the origin of history. Unified, knowing, and autonomous, the human being seeks a political system which guarantees freedom of choice," which, as it turns out, is Western democracy. ${ }^{4}$ Alien phenomenology continues the theoretical effort to debunk the sovereignty of this liberal humanist subject, not only by placing people on the same ontological level with other objects, but also by discovering in "things" many of the qualities previously seen as the sole property of people.

3 In Vibrant Matter, Bennett tackles the subject-object binary with a new form of anthropomorphism that ascribes to objects both agency and a political role, setting up what Manuel de Landa called a "flat ontology," a space in which humans and objects, even imaginary ones, are equal to one another in terms of their "being." Hayles enters into the discussion from the machine side of the cyborg as human-machine hybrid. She begins with the posthuman premises that first, information is separable from its material substrate, which dissolves the distinction between biological life and computers; and second, "there are no essential differences or absolute demarcations between bodily existence and computer simulation, cybernetic mechanism and biological organism, robot teleology and human goals". ${ }^{6}$ Hayles questions in particular the assumption that information can be separated from the bodies, whether human or machine, that transmit it. She imagines instead the role played by "virtual bodies," recalling but also resisting the historical process by which bodies and information have been divorced from one another in posthumanism. While Bennett and others in the Object Oriented Ontology (O00) strain of thought emphasize the agency of objects previously considered to be inert and silent, Hayles points to the solidity of previously abstract information. Both strands of thought disrupt the subject-object binary in the interest of acknowledging the embodied "being" of an expanded cast of actors on the world's stage.

In a recent application of posthumanist philosophy to Shakespeare studies, Douglas Lanier has offered the rhizome of Deleuze and Guattari as a persuasive paradigm for Shakespearean relations that deviate from the fidelity paradigm. According to Lanier's reading of Gilles Deleuze and Felix Guattari:

A rhizomatic structure [...] has no single or central root and no vertical structure. Instead, like the underground root system of rhizomatic plants, it is a horizontal, decentered multiplicity of subterranean roots which cross each other, bifurcating and recombining, breaking off and restarting [...] What is more, a rhizome has no central organizing intelligence or point of origin; it may be entered at any point, and there is no a priori path through its web of connections.

5 The rhizome as literary model unseats "Shakespeare" as the putative fons et origo of adaptations by emphasizing the equality of all roots within its tangled, always changing structure:

A rhizomatic conception of Shakespeare situates "his" cultural authority not in the Shakespearean text at all but in the accrued power of Shakespearean adaptation, the multiple, changing lines of force we and previous cultures have labeled as "Shakespeare," lines of force that have been created by and which respond to historical contingencies. ${ }^{8}$

Lanier's argument is incisive and persuasive, and has proven influential for appropriation/adaptation studies. It leans, however, toward Bennett rather than Hayles in the opposition I have sketched out between their opposed takes on posthumanism. The rhizome, however de-centered, is still an organic model rooted in the familiar world of 
human beings, just as Linda Hutcheon's definition of adaptation embraced the term's connections to biological models. ${ }^{9}$ To my mind, Bogost's alien phenomenology, which weaves a path between material objects and networks as models for posthuman relations, will prove more useful for the range of digital objects discussed in this essay. Think of alien phenomenology as the computational counterpart to Deleuze and Guattari's rhizome.

In defining alien phenomenology, Bogost carefully charts a middle way between materialism and network-theory as models for understanding objects and their relations with one another. He begins by considering Bruno Latour's actor-network theory and its governing metaphor of the "assemblage." Latour defines the "social" realm as a network peopled not by subjects and objects but by "actants," both human and non-human. Their relationships within these networks are at once semiotic and material and require constant activity and performance to exist. But for Bogost, Latour's model locates relationships too restrictively as outside rather than inside "the being of a thing," and perhaps more important, his governing metaphor limits the operations of chance and chaos: "The 'network' is an overly normalized structure, one driven by order and predefinition." Bogost leans instead to Latour's later, more unruly concept of the "imbroglio," in which "it is never clear who or what is acting". ${ }^{10}$ Bogost also reworks object oriented ontology (referring to a number of theorists, although not to Bennett) to emphasize ever smaller objects and specifically to incorporate the computer into its theoretical purview. He offers objections to 000 as well, in that this approach tends to see objects as existing in a vacuum, a side effect of granting them political agency, and works with a too restrictive sense of what entities qualify as objects. If in the network relations are over-determined, in 000 objects are too isolated. Finally, Bogost faults both network theory and 000 for being too human-centered, considering objects as agents largely in terms of their significance for people; for him, the posthuman is still too human.

7 To challenge both the emphasis on individuality of separate objects in object oriented ontology and the inherently orderly nature of Latour's networks, Bogost works with a vocabulary of "units" and "systems." Paradoxically, units (formerly objects) both populate and constitute systems, and systems then become parts of other systems. Bogost imagines these units as not merely arranged without hierarchy on a plane, as in de Landa's "flat ontology," but as coming together in a dense, concentrated point. These infinitely dense and yet capacious black holes, which are the foundation of what Bogost calls his "tiny ontology," are promiscuous, and the systems in which they engage with one another are "held together tenuously by accidents". ${ }^{11}$ Bogost wants to see all kinds of "units," from people to pixels, xylophones to XML markup, as they exist for themselves and as they relate to one another and to do so without either resorting to anthropomorphism or dematerializing altogether the object within its networks.

\section{Alien Shakespeare, 1: YouTube's Tiny World}

Looking at the coalescence of units by chance or accident into tenuous and shifting systems - an alien phenomenology grounded in tiny ontology - provides a good model for looking at the varied objects of Shakespeare 2.0, in both new media and digital humanities projects. Probably the paradigmatic new media platform for Shakespearean creators and consumers is YouTube. It is relatively simple to find the "alien" and the 
"tiny" in YouTube Shakespeare, at least on a metaphorical level. Just think of the fad for LEGO Macbeths first chronicled by Peter Holland in 2009. ${ }^{12}$ The Legos, with their boxy bodies, hard surfaces, and impassive visages (see Figure 1), are the indirect progeny of Forbidden Planet's Robby the Robot, now scaled down for YouTube's small screen and iMovie's brief scene (see Figure 2). YouTube's aesthetic is generally tiny and disaggregated. Favorite genres are the film clip and trailer, either taken wholesale from a professional site or created by amateurs. Miniature figures, LEGOs and sock puppets foremost among them, are popular in amateur productions. Small ensembles of highschool students, from soliloquies to pairs and quartets, are the norm.

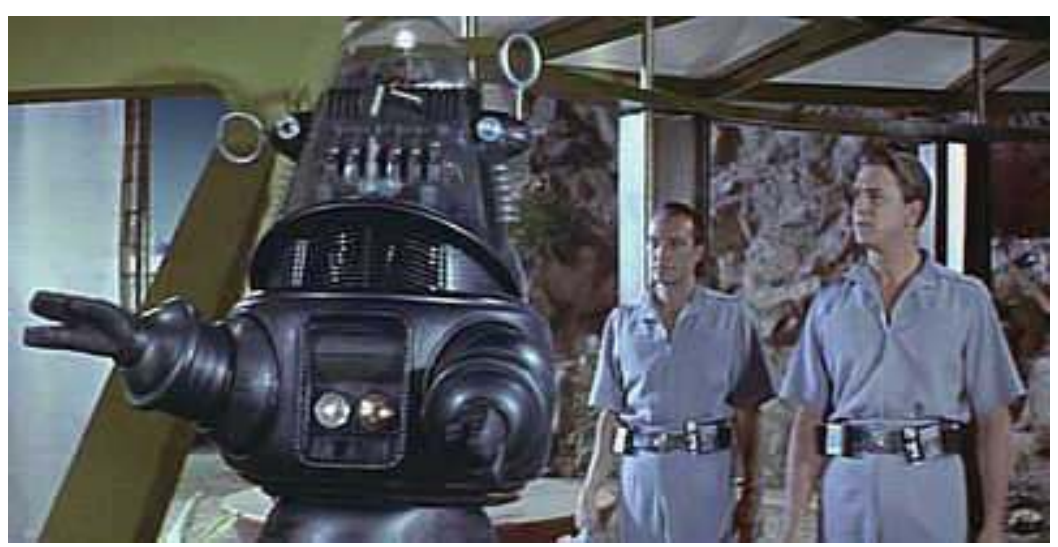

Figure 1: Fred M. Wilcox, Forbidden Planet, 1956: Robby the Robot.

Screen grab, Wikipedia, https://en.wikipedia.org/wiki/Robby_the_Robot\#/media/ File:Robbie_Forbidden_Planet.jpg (fair use)

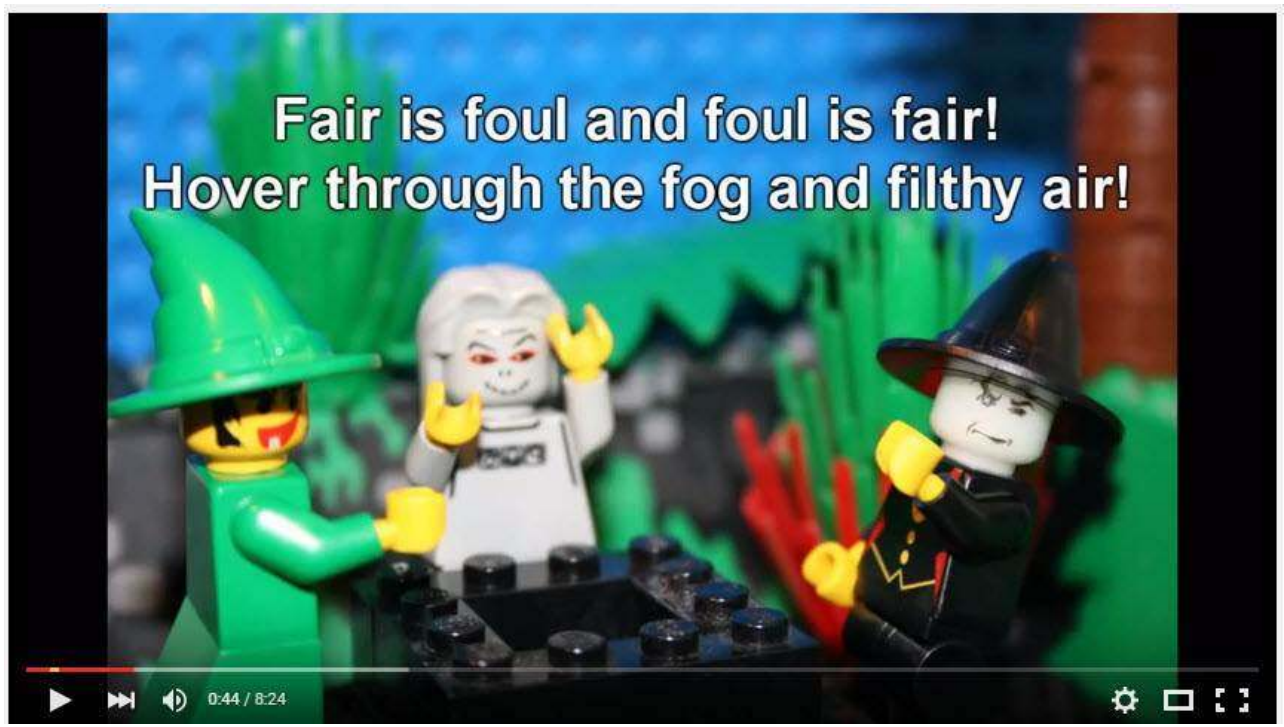

Figure 2: Macbeth Lego: The Movie by steamworks, 2009.

Screen grab (YouTube video). URL: https://www.youtube.com/watch?v=pKAw6UBziBY.

9 Regarded through the lens of tiny ontology, the little films of YouTube are engaged with smaller, even harder-to-recognize objects. There multiple actors on the YouTube scene, many of which are abstract and difficult, even possible, to penetrate. First, there are the metadata provided by the video's poster; in the case of YouTube Shakespeare, tagging 
tends to be minimal and thus unhelpful for future searches. Furthermore, misleading metadata - for instance, the ploy of using the label "porn" to increase a video's visibility can also play a role. ${ }^{13}$ So do the disembodied "voices" of commenters who, as Ayanna Thompson has demonstrated and Valerie Fazel has theorized, may be major disruptors in the viewer's experience of a video..$^{14}$ The secret sharers on the YouTube site, significantly, also include such an unimaginable actor as the closely guarded YouTube algorithm, which determines the formula by which videos are ordered in the site's page rank. The algorithm is complicated, partly dependent on the sheer number of hits a given video receives and partly not, and it is most emphatically shrouded in secrecy. ${ }^{15}$ More generally, as Ted Slavin has discussed, algorithms "talk" primarily to one another and "decide things" amongst themselves. ${ }^{16}$ Algorithms therefore are computational "units" with a good bit of agency, combined with a lack of transparency. The "configurative" relations between and even the internal machinations of an algorithm go on with or without us humans, as Bogost would be quick to point out. They are truly posthuman actors on a vast cyber-stage coming together in varying configurations through chance encounters.

\section{Alien Shakespeare, 2: The Textual Power of Little Things}

Digitized texts also offer classic examples of "alien Shakespeare." The disaggregation of a Shakespearean text into "units" - semantic segments, words, lines, or even morphemes is the condition of existence for digital texts, necessary for such features as text formatting and a workable search engine. Such disaggregation is made palpable by a simple Wordle, which creates spatial constellations of words from linear text using size, color, and proximity to indicate prominence and affinity among individual words. Figures 3 and 4 show two different Wordles created from the Folger Digital Text version of Shakespeare's Sonnet 18. There is a perceptible kinship between the two; "thou" and "fair," for instance, are dominant in both images. In the first Wordle, however, the word "thou" stands by itself in lonely splendor at the top right (see Figure 3), while in the second it is cushioned between such words such as "declines," "breathe," and "life," suggesting an object on a trajectory between birth and death (see Figure 4). Of course, "thou" as a Shakespearean object or unit also forges some affiliations that might frustrate the allegorizing Shakespearean. Why, for instance, is "shake" prominent in one Wordle but not in the other? Or for that matter, how does the noun "gold" fit with the biographical flow of the poem in the second Wordle? The answer, of course, is that it does not fit. "Gold" is alien to "thou," at least according to my reading of the verbal configuration of Figure 4. The visual interface conceals the object's "secrets," which lie hidden within the depths of the application. 


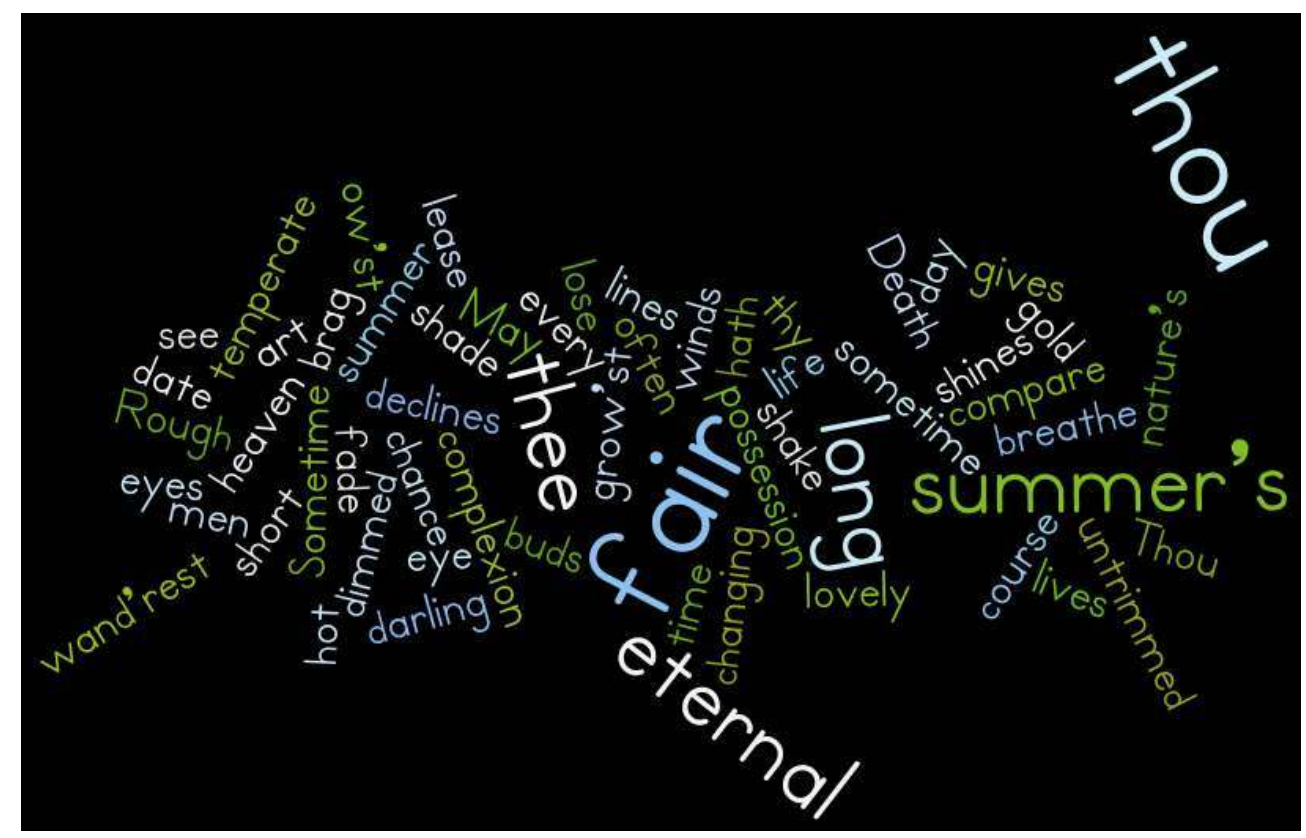

Figure 3: Wordle constructed for William Shakespeare, Sonnet 18.

http://www.wordle.net/.Text from the Folger Digital Texts, http://www.folgerdigitaltexts.org/.

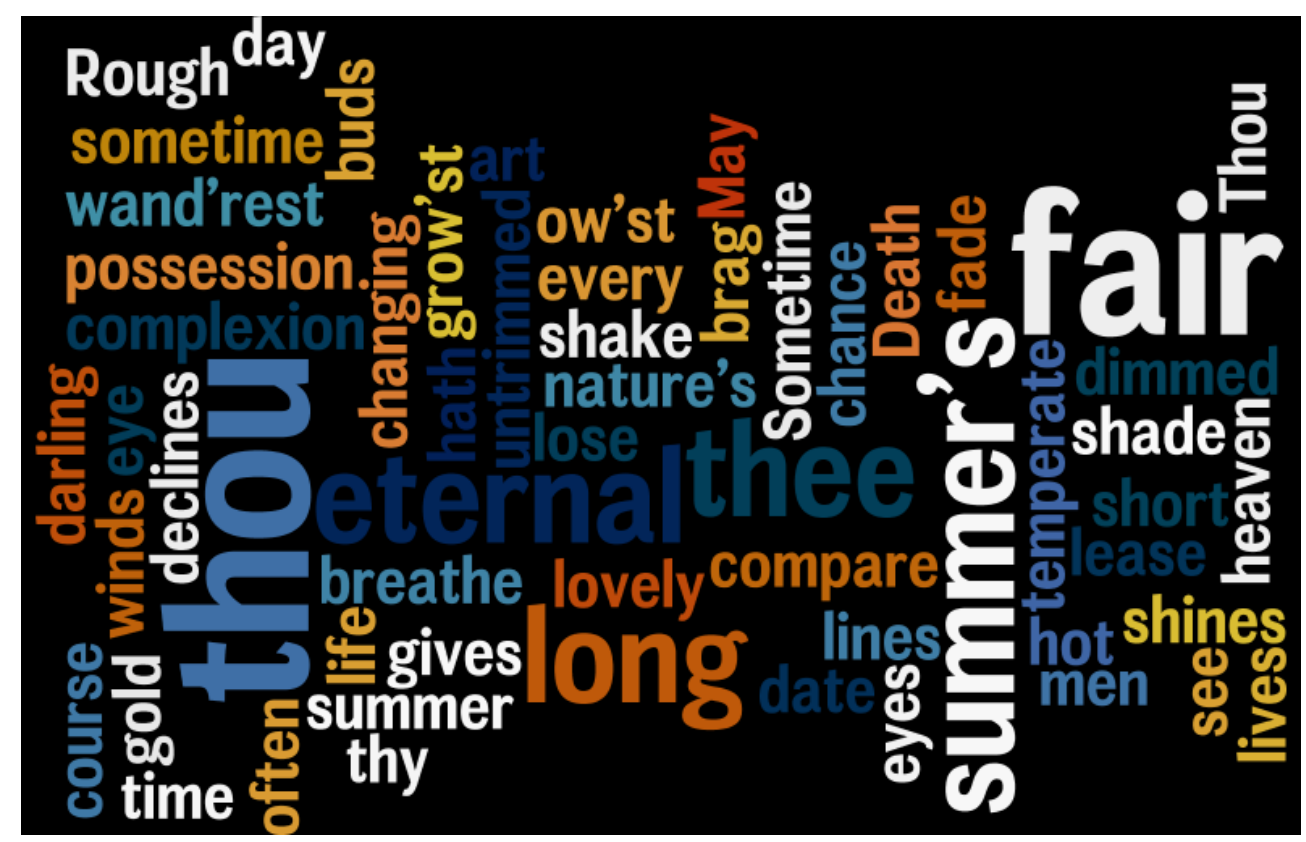

Figure 4: Another Wordle created from Sonnet 18.

Text from the Folger Digital Texts, http://www.folgerdigitaltexts.org/.

11 Alien phenomenology is present, but less obvious, in digitized Shakespeare texts designed for reading and study. Digitized texts, by nature, are disaggregated, meant to be carved up and recombined. Take, for instance, a simple word search on "black" within the text of Othello from the Folger Digital Texts. At right pops up the familiar string of abbreviated references, offering the ability to click through to each textual reference in the larger context of its digital page (see Figure 5). The interface that makes searching simple and 
intuitive, however, belies the hidden structure of the Extensible Markup (XML) coding that lies beneath and the style sheet that organizes and formats the play's digital pages. Looking at the "Page Source" via an Internet browser shows the Shakespearean text - the words that would be heard on stage, on screen, or in the reader's aural imagination - as being nearly lost within the dense web of coded instructions intended for computer and browser, units/objects/agents that are resoundingly indifferent to the presence or absence of the readers for whom they are destined. (In Figure 6, the stage direction "Enter Roderigo and Iago" and Roderigo's opening line, “... never tell me!" are circled and highlighted.) Looking at the code beneath the web interface reveals a whole host of units/ objects/agents necessary to convey Iago's scripted words - and they are indeed alien to anyone familiar with Othello as an acted, screened, or printed text. "Iago" and his speech acts are merely two units in a complex configuration of agents.

ACT 1

Scene 1
Enter Roderigo and Iago.
RODERIGO
(Tush,) never tell me! I take it much unkindly
That thou, Iago, who hast had my purse
As if the strings were thine, shouldst know of this.
IAGO ('Sblood,) but you'll not hear me!
If ever I did dream of such a matter,
Abhor me.
RODERIGO
Thou toldst me thou didst hold him in thy hate.
LAGO Despise me
If I do not. Three great ones of the city,
In personal suit to make me his lieutenant,
Off-capped to him; and, by the faith of man,
I know my price, I am worth no worse a place.
But he, as loving his own pride and purposes,
Evades them with a bombast circumstance,
Horribly stuffed with epithets of war,
(And in conclusion,)
Nonsuits mv mediators For "Certes" savs he

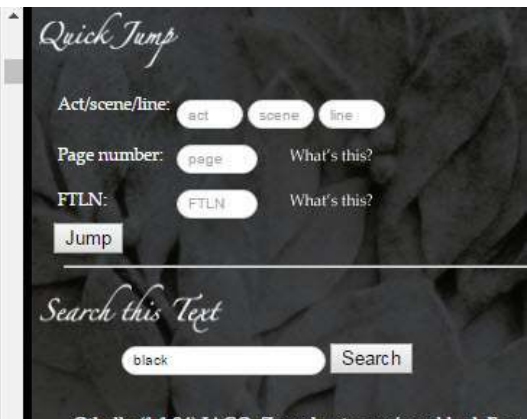

Othello (1.1.94) IAGO Zounds, sir, you're robbed. For shame, put on your gownl/ Your heart is burst You have lost half your soul. / Even now, now, very now, an old black ram / Is tupping your white ewe. Arise, arise! / Awake the snorting citizens with the bell, $/$ Or else the devil will make a grandsire of you / Arise, I say!

Othello (1.3.327) DUKE: Let it be so. / Good night to everyone. And, noble signior, / If virtue no delighted beauty lack, / Your son-in-law is far more fair than black.

DOWNLOAD THIS TEXI

BUY THE FOLGER EDITION

\section{Figure 5: Beginning of Othello, Folger Digital Texts.}

Screen grab. URL: http://www.folgerdigitaltexts.org/?chapter=5\&play=0th\&loc=p7

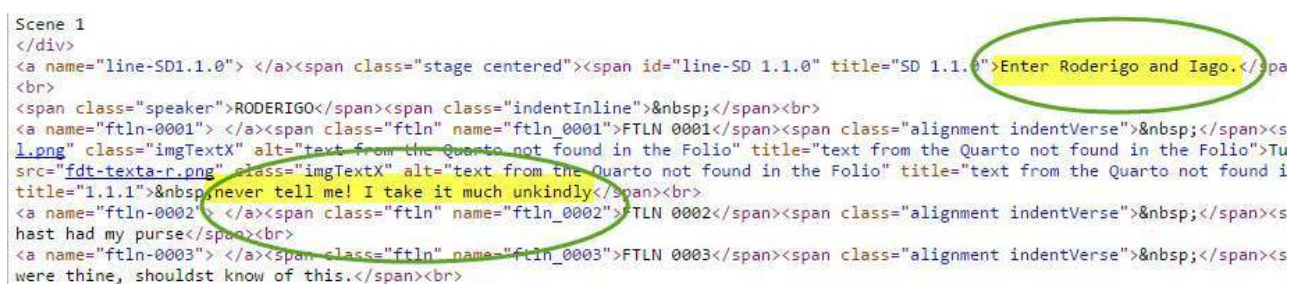

Figure 6: Page Source for beginning of Othello, Folger Digital Texts.

Screen grab. URL: http://www.folgerdigitaltexts.org/?chapter=5\&play=0th\&loc=p7

The code undergirding the Folger Digital Texts Othello is, of course, carefully vetted and fully operative. But marking up text invites mistakes, and a stray mark can have real 
consequences. Here is an example from the production of Borrowers and Lenders: The Journal of Shakespeare and Appropriation. The online journal builds its webtexts and PDF displays from a core document marked up in XML (Extensible Markup Language). Every item that can be marked in an essay has a tag that defines that item in terms not of display (how does it look?) but of function (how would a search engine, for instance, treat it? As a proper name, a book title, an image, and so forth?). One of the easiest mistakes to commit when highlighting text and clicking on a tag to "mark" its identity is to leave something outside the tag. This happens most frequently with the References section, the culprit usually being a stray period or full stop outside the close angle bracket of each marked reference item. The mark is so tiny, but the result is immediate and tangible. That stray period means the difference between a nicely displayed essay and a blank page. What a wicked black hole that misplaced full stop proves to be!

13 A more complex example of alien phenomenology and tiny ontology at work in digitized Shakespearean texts can be found in the computational studies with "big data" that are used most frequently for authorship studies. As Hugh Craig and Arthur Kinney explain in their useful account of the premises and methods that inform computational study in Shakespeare, Computers, and the Mystery of Authorship, while striking words and uncommon words might catch the reader's attention most readily, the process of tracking authorial style through large corpora often depends on common words. Based on the hypothesis that each person's brain "contains a lexicon of words" as well as a mental grammar, Craig and Kinney argue that we need "to pay attention to the lexicon (the number and pattern of common words - common to a culture, common to an individual writer), as well as [to] rare or suddenly new words and patterns of words." ${ }^{17}$ Conclusions about broad literary concepts thus can rely on the most mundane features of language. Take, for instance, genres of Shakespearean play: according to Craig and Kinney, pronouns "are among the strongest markers of genre ( $m e$ is unusually common in Shakespeare comedy, as we and they are in Shakespeare's Roman plays)". ${ }^{18}$ Computational studies, Craig and Kinney conclude, reveal to us that such little and colorless words are "not insignificant structural material, but in fact vary in concert with almost any differentiation of text one might think of, from authorial styles to national linguistic differences". "19 "Shakespeare"'s individuality as an author, therefore, paradoxically depends on a computer's detection of a common lexicon of function words in his printed plays; he is, in fact, nothing more or less than varying webs of little words based on a mechanized counting of these words within segments of digitized text carved up by length rather than poetic or semantic considerations.

For an even more "alien" view of Shakespeare's texts that focuses on units smaller than the word, we might look at the Shakespeare Quartos Archive, which builds on the British Library's Shakespeare in Quarto website. ${ }^{20}$ To date, the site offers only a Hamlet prototype; for this play, however, the project offers both facsimiles and XML transcriptions of all the Hamlet quartos. Visitors to the site can compare different quartos of Hamlet and see up close the marginalia that have long been sequestered in rare book libraries. Figure 7 offers an example of such digitized marginalia, which is an inserted stage direction, "laying his Hand on Laertes Head," to accompany the blessing that Corambis (aka Polonius) gives to his son prior to offering his famous paternal advice. William Sherman has analyzed markings of this kind in material books through the lens of book history, and recent developments in textual forensics have gleaned from these same books information ranging from the provenance of paper to the characteristics of previous 
owners. ${ }^{21}$ But in the digitized environment of the Shakespeare Quartos Archive, neither paper nor handwriting can yield material clues to the agent(s) that produced that stage direction. Furthermore, the marginalia's author has multiple identities. Within the XML transcript, the annotator is identified as "\#ab" and the text's location as "\#bli" or British Library (Figure 8). The page's metadata identifies the annotator as "hand-anon2," an unknown annotator from the seventeenth or eighteenth century. In the digital environment, the "author" of this annotation is a configuration of various signs or units, in Bogost's terminology: the handwriting, in its pixelated rendering; the identifiers "\#ab" and "hand-anon2"; and the ghostly hand of a long-dead person who may or may not have left biological traces within the book housed in the British Library. ${ }^{22}$

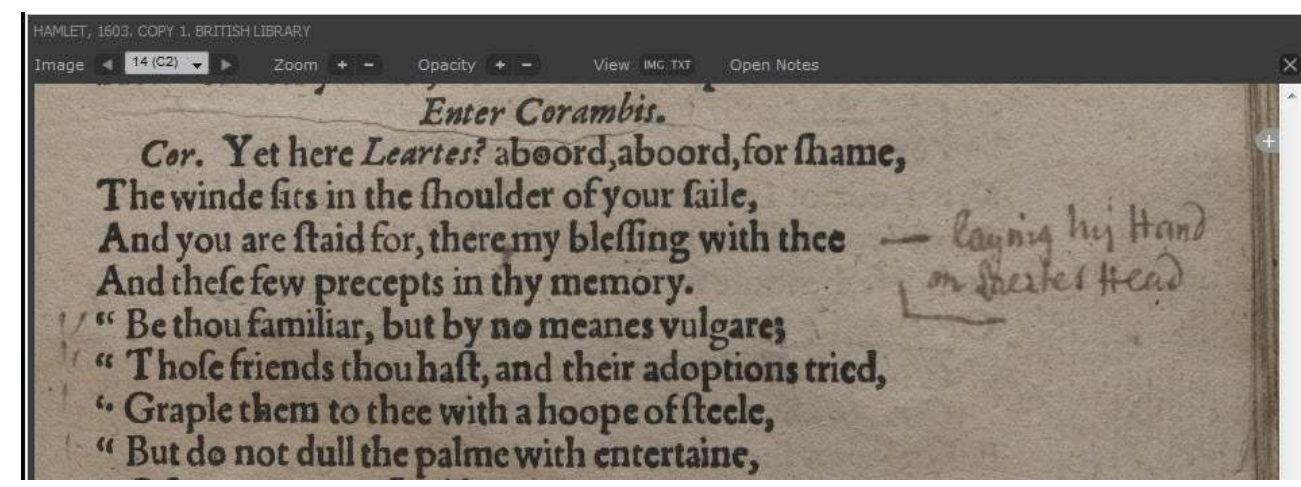

Figure 7: Hamlet, Q1, BL Shelfmark C.34.k.1. Q1, Shakespeare Quartos Archive.

Screen grab. URL: http://www.quartos.org/main.php.

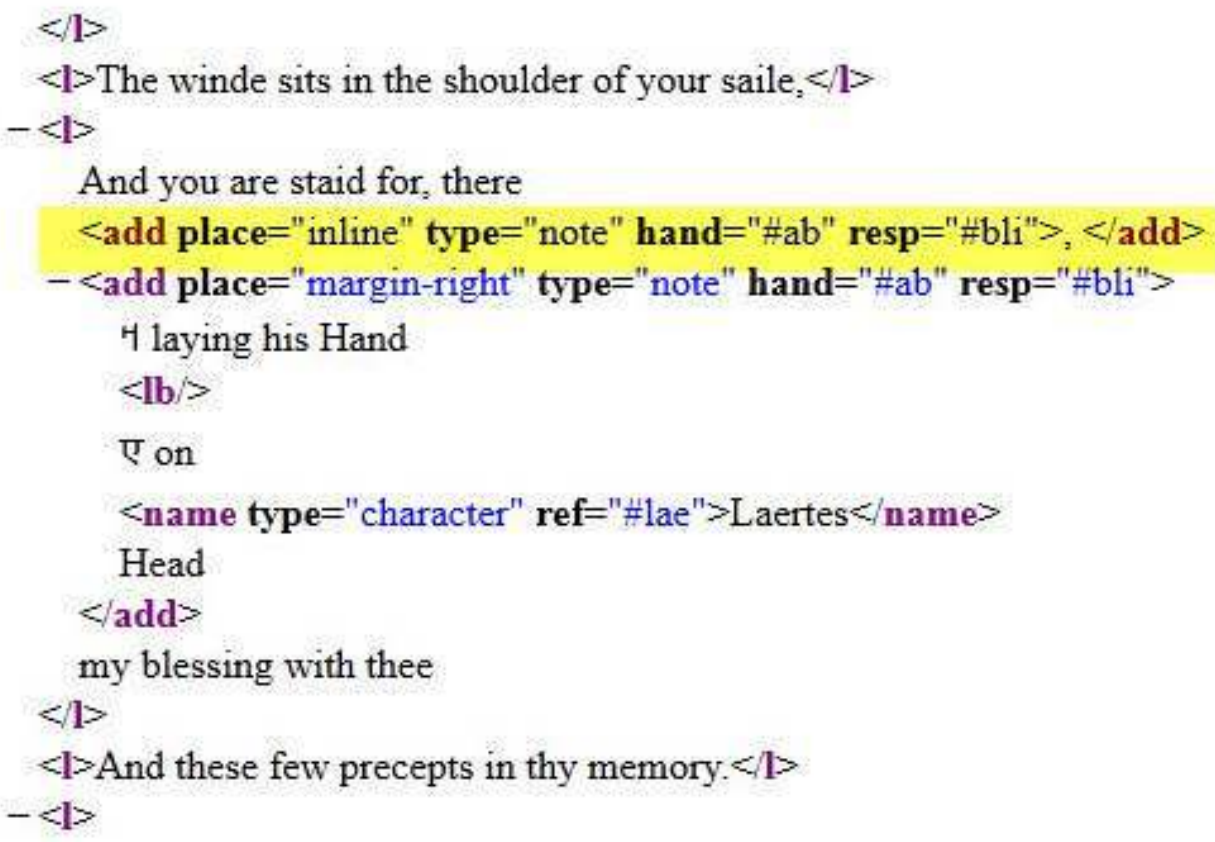

Figure 8: XML transcription of Hamlet, Q1, BL Shelfmark C.34.k.1. Q1, Shakespeare Quartos Archive.

Screen grab. URL: http://www.quartos.org/main.php. 


\section{Alien Shakespeare, 3: Life as an App}

15 The relevance of Bogost's alien phenomenology to Shakespeare 2.0 is most striking, perhaps, in a hybrid space that combines video and/or audio with text - the Shakespeare app. There are a number of these on the market, aimed mostly at the educational sector. The Shakespeare app exacerbates the disaggregation of "Shakespeare" perpetrated by digital texts of the plays, adding more agents and more voices. In the Luminary app of Macbeth, sponsored by the Folger Shakespeare Library, the digital paratext offers an opportunity to consult the opinions of Shakespeare critics, and also the ability to select which critic one wants to consult at any given moment. The clips of expert commentary are like the substantive notes in a printed text, or film clips used in the classroom. As Laurie Osborne argues, the film clip functions as a type of Shakespearean quotation, thus enforcing the primacy of Shakespearean text over performance. Running teacher commentary over the clip, furthermore, can function as an authoritative voiceover that subordinates actors, characters, and bard alike to the central classroom authority. ${ }^{23} \mathrm{In}$ practice, the film clip can be a conservative force valorizing the printed text that it aims to replace. The Luminary app perhaps seems more democratic because it places different "voices" on equal footing and can foster quite contingent relations among its assorted parts; to some extent, the reader can wander at will through the app's virtual spaces. Nevertheless, the main experience is of text enhanced by other objects of sight and sound.

A more tangled interaction between Shakespeare text and video application can be seen in the Shakespeare in Bits Macbeth. For each in its series of plays popular in K-12 settings, Shakespeare in Bits offers the complete plays in one-minute segments. The screen is divided in half. At left is an animated video of the scene with soundtrack, with the text at right. Jennifer Ailles suggests that Shakespeare apps challenge the notion of the "discrete book" by providing a "free flow of text," most frequently on the small screens of phones and tablets. ${ }^{24}$ We can see how data flows in the Macbeth app as within each screen, the words spoken by the cartoon character at left are colored red. Thus, the text seems to scroll down the page as the cartoon moves its mouth (see Figure 9). ${ }^{25}$

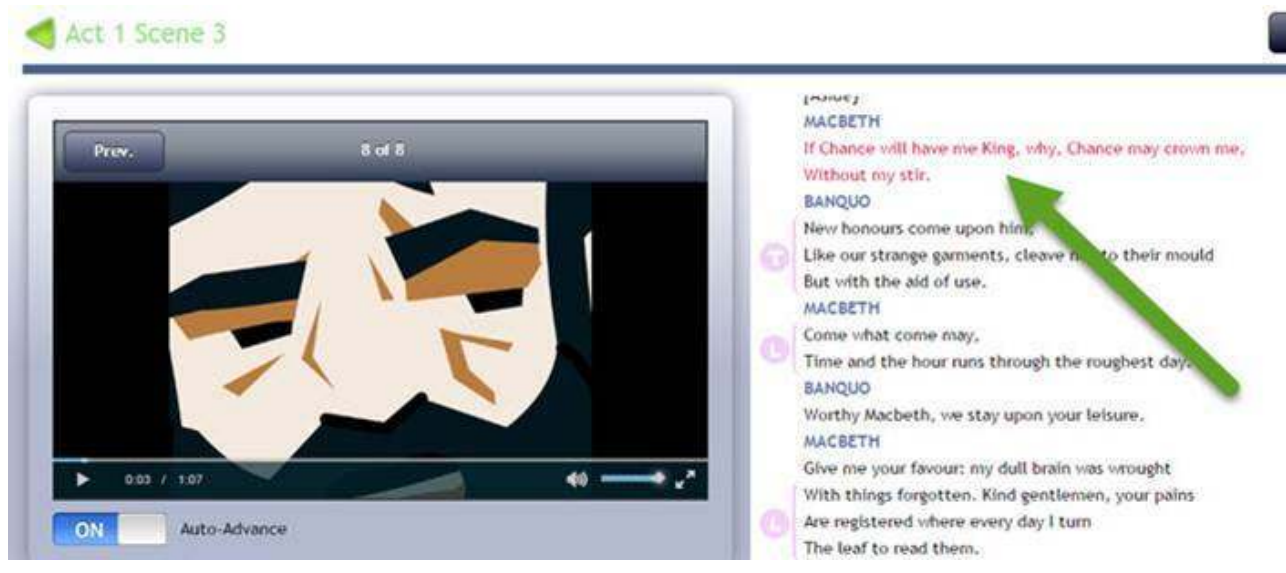

Figure 9: Shakespeare in Bits app of Macbeth, with text being spoken highlighted in color at the right part of the screen.

Screen grab. URL: https://siblive.shakespeareinbits.com/siblive2/. 
The notion of data flow, however, treats the digital information in a Shakespeare app as too disembodied - without agency, without affect. As a digital artifact, the Shakespeare in Bits Macbeth is less a data flow than a system or network of tiny units that exist in changing relations that are, at bottom, accidental. As an example at a fairly macroscopic level, consider the relation between animation and soundtrack. While the animation was designed for this particular app, the soundtrack, as it turns out, comes from the venerable Naxos audiobooks, where the three witches were played by Annette Badland, Joyce Henderson, and Pauline Lynch. Fiona Shaw read the part of Lady Macbeth. ${ }^{26}$ It is easy enough to see this animation as alien Shakespeare. The aesthetics behind the witches' appearance leans towards print comics or manga. For dialogue, the camera favors shot-reverse-shot close-ups of the conversationalists, anchored by periodic establishing shots from a medium distance. Figure 10 shows the witches at the moment when they begin to intone "Fair is foul, and foul is fair." The coolly detached, almost ethereal voices of the Naxos audiobook witches contrasts strongly with the gothic and somewhat masculine appearance of their cartoon equivalents. There is also an additional, extradiegetic scene, which shows a disturbed man's face in close-up to accompany some huffing-and-puffing on the soundtrack. In its original aural context, those noises announce the imminent arrival of the Bloody Sargeant, who is replaced in the app by what can only be the Thane of Cawdor, who has made regular appearances in Macbeth films following the Roman Polanski version, with the panting breaths now signaling that character's distress as he awaits execution. ${ }^{27}$

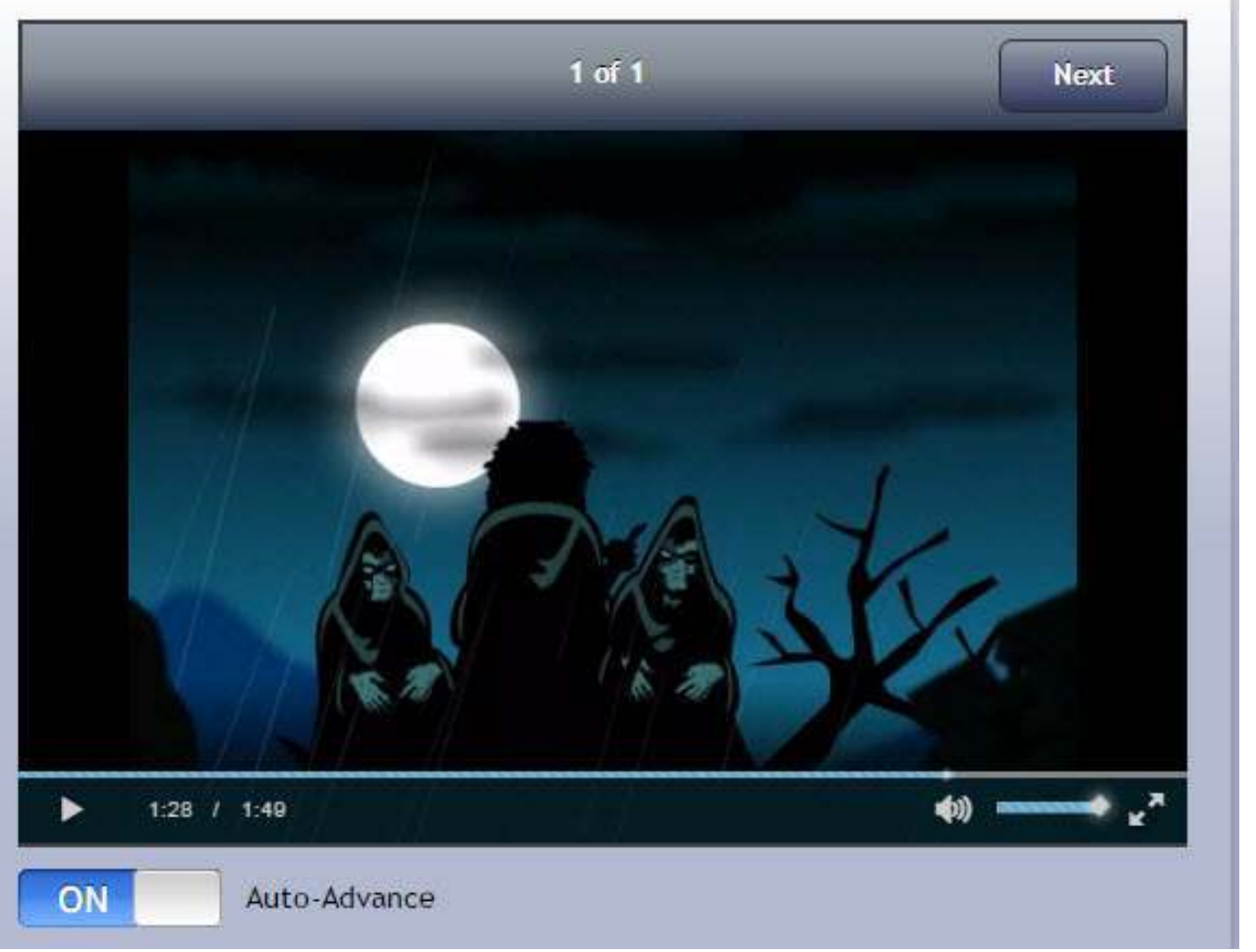

Figure 10: Witches from the beginning of Macbeth ("Fair is Foul"), Shakespeare in Bits Macbeth public demo.

Screen grab. URL: https://siblive.shakespeareinbits.com/siblive2/. 
Looking at the Shakespeare in Bits Macbeth as a collection of units or objects with equal agency and affective power, we can see their contingent coming together as more energetic and more vexed than the notion of disembodied data flowing freely would allow. Characters mouth words we never hear, while text comes to life through the red highlighting; even when mouths and words are in sync, they exist in separate worlds. As the text scrolls relentlessly down the screen in counterpoint with a close-up of the animated character's mouth, the Shakespeare in Bits app calls attention to the fragmented, even disjointed, nature of its operations. Images, sounds, stylized faces and moving letters come at us from all sides. This is alien Shakespeare 2.0.

com see a comparable working out of contingent, or even chance, relationships in the scene where Lady Macbeth reads her husband's letter. Again, the relationship between voice and visual appearance of the character is only contingent. While in an animated film the actor supplying a character's voice is presumably chosen to fit that character's physical appearance and behavior, the Lady Macbeth of Shakespeare in Bits is voiced by Fiona Shaw, whose Naxos performance stands at a considerable temporal distance from the creation of the app. The choice of voice to match with the cartoon Lady Macbeth, furthermore, is most likely a matter of availability, convenience, and copyright conditions as much as aesthetic considerations. Fiona Shaw and Lady Macbeth are configured into a system whose existence is contingent on a host of factors: the digitized voice in the app (which remediates the LP record, cassette tape, and CD, all previous delivery methods of the audiobook), pixelated cartoon, and scrolling text of varied colors all exist on the same plane; ontologically, furthermore, each one is equal to the others.

Not only do the parts of Shakespeare in Bits's app lead a separate existence while combining with one another in contingent or chance relationships, but the crafted narrative forms extramural relations with objects beyond the screen. In 1.5, after encountering a panoramic view of Castle Macbeth to set the scene, we find Lady Macbeth in her bath, reading by candlelight the letter from Macbeth (Figure 11). As Fiona Shaw's controlled, mellow voice reads the letter, the Lady Macbeth figure is shot in a series of close-ups that focus on different parts of her face; the animation records clearly through these close-ups the figure's progression from mild interest to surprise (Figure 12), and finally to complicity, as the letter entrusts Macbeth's secret to his wife: "Lay it to thy heart, and farewell" (Figure 13). The visual synecdoches, focusing on key body parts, are in tune with dominant image strands in the play. Yet there remains one fractious object: that bathtub. Why, we might ask, is this the setting chosen for act 1 , scene 5 ? 


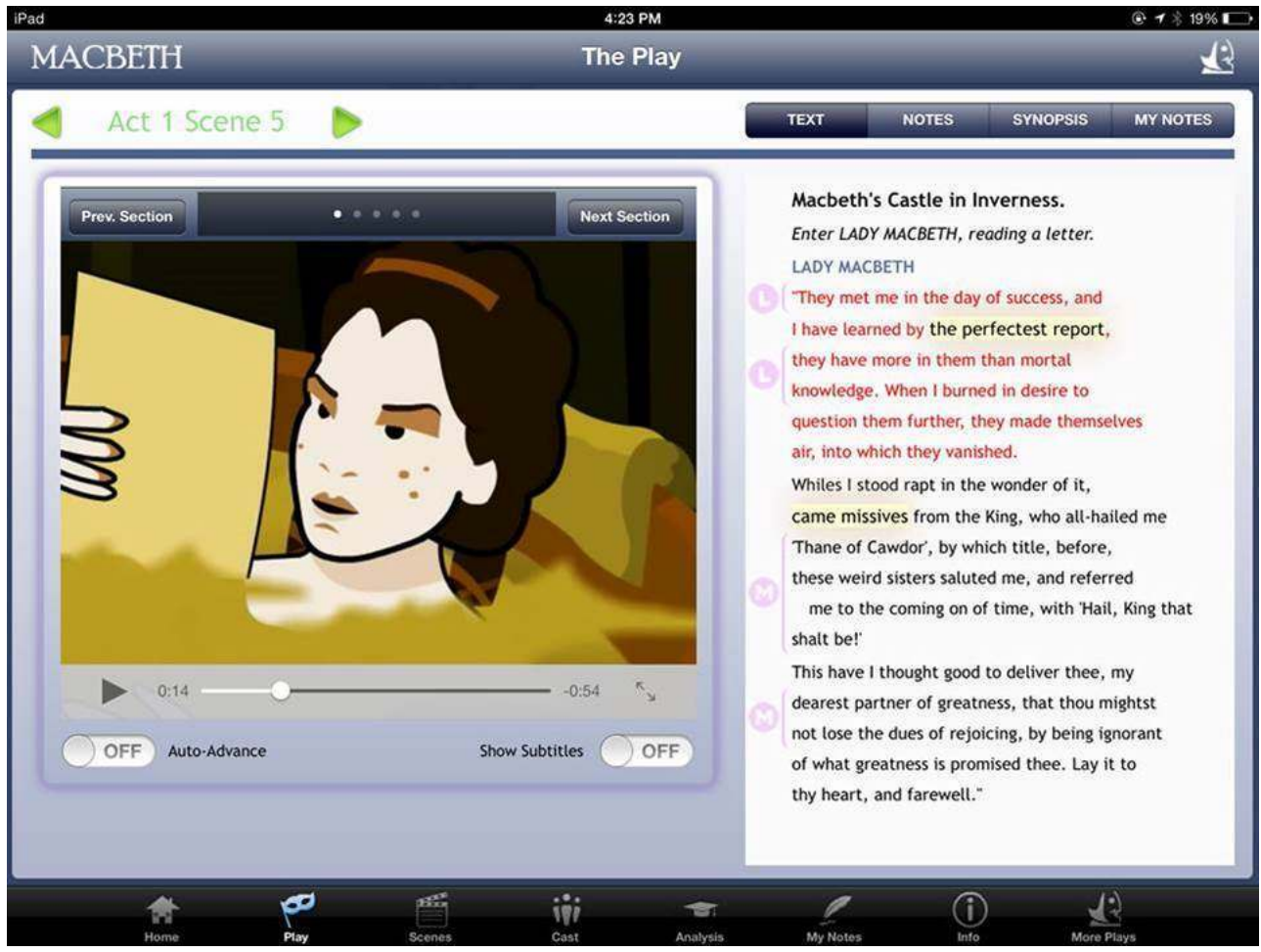

Figure 11: "They met me in the day of success," Shakespeare in Bits Macbeth, screengrab.

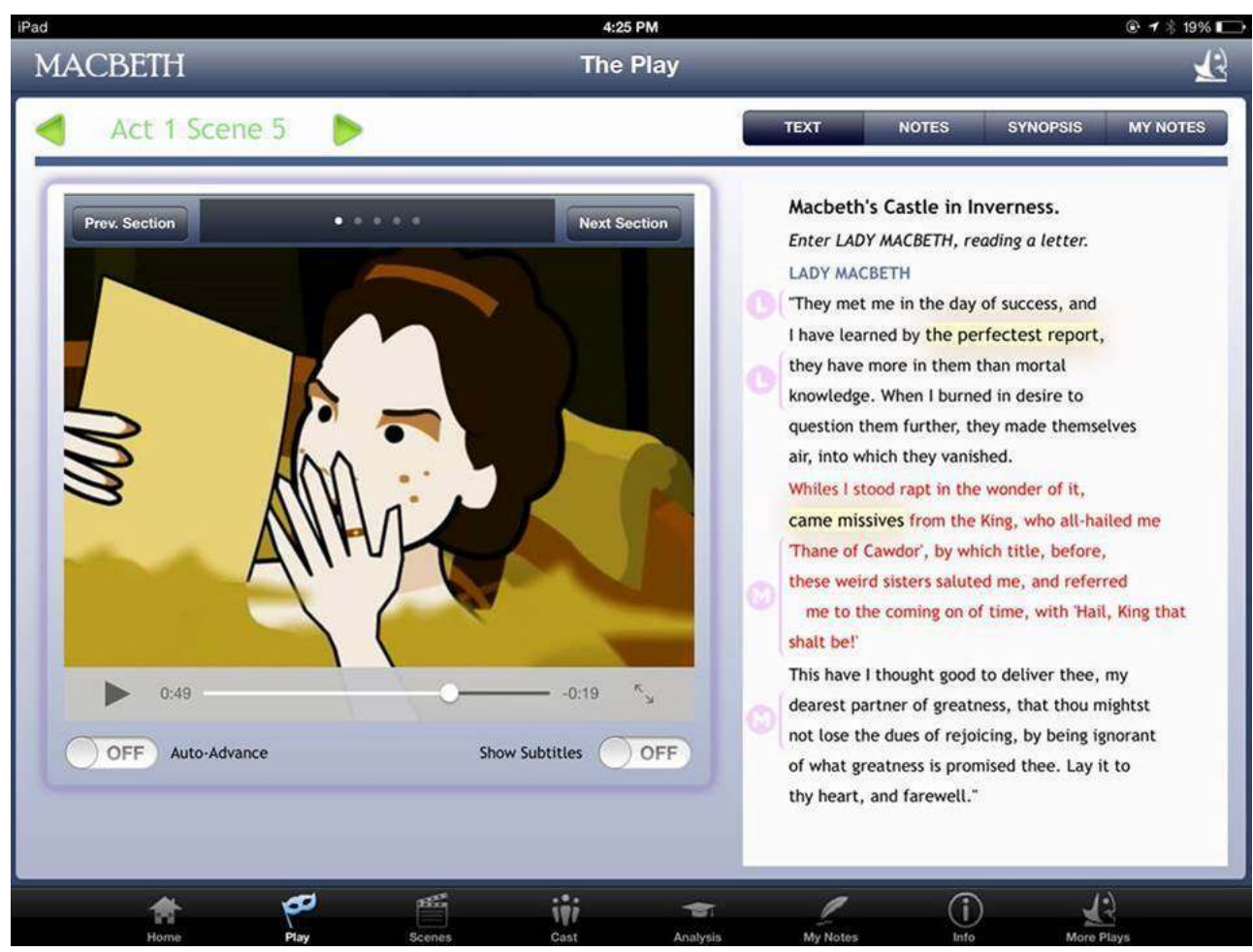


Figure 12: "While I stood rapt in wonder of it," Shakespeare in Bits Macbeth, screengrab.

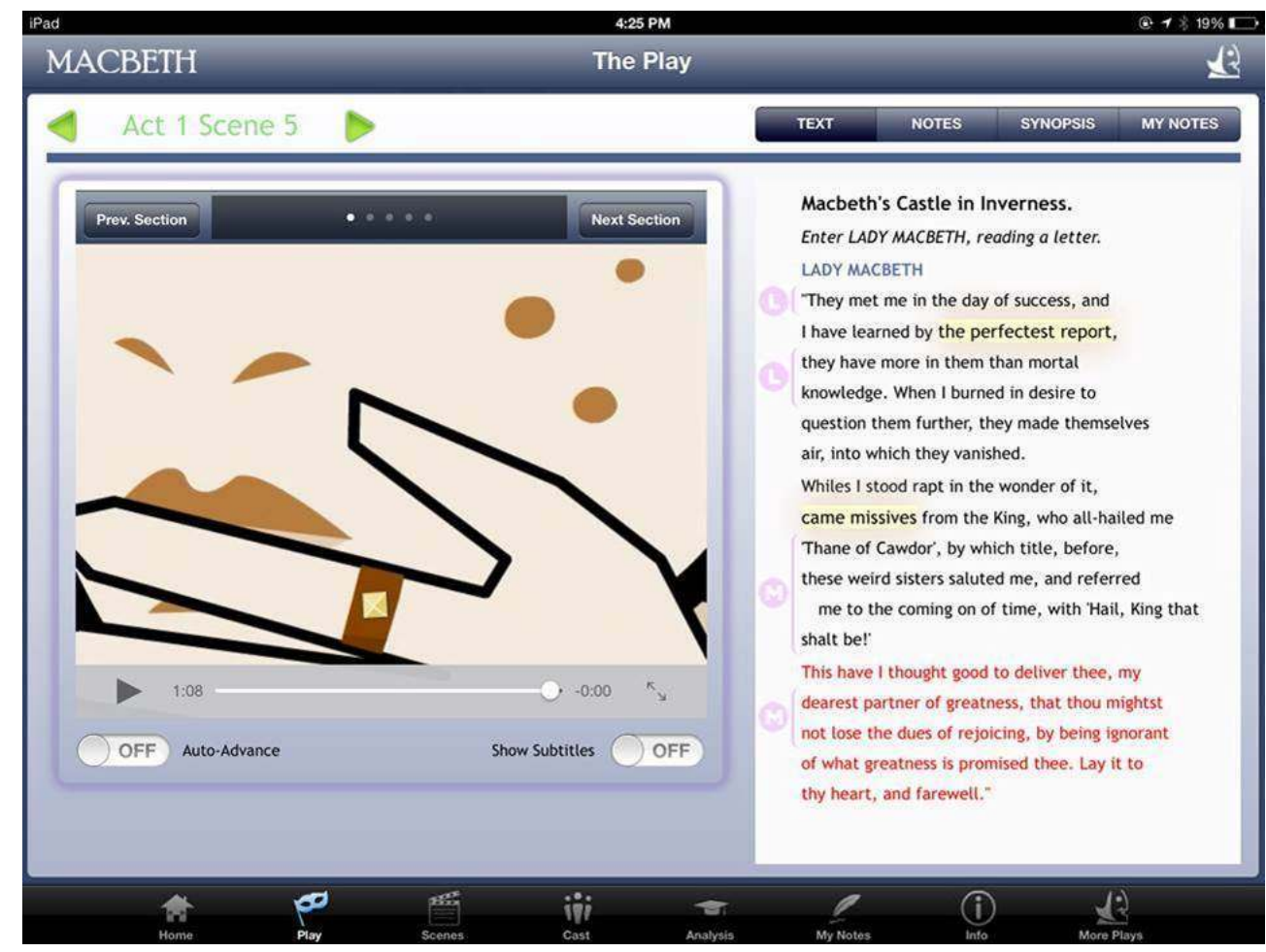

Figure 13: "Lay it to thy heart, and farewell," Shakespeare in Bits Macbeth, screengrab.

The setting makes no choice in terms of the diegetic narrative, for if Lady Macbeth really were to lay the letter to her heart, it would dissolve in the bath. Placing her in the tub, of course, does allow us to register the cartoon figure's shifts in mood, and the bath is linked vaguely to the text as a proleptic version of the basin in which Lady Macbeth will soon wash the blood of Duncan off her hands. The choice also has dramatic and cinematic analogues. The original Lady Macbeth reading her husband's letter in the bath may well be Harriet Walters, playing opposite Anthony Sher in Gregory Doran's 1999 Macbeth for the Royal Shakespeare Company. But that historic production is probably not in play in this context. In a more likely popular culture precedent, Macbeth and his wife strip naked to get rid of Duncan's blood in a similar bathtub for Punchdrunk's long-running piece of immersive theater, Sleep No More (Figure 14); and in the 2006 film of Macbeth by Geoffrey Wright, we first meet Lady Macbeth relieving stress by taking to a candlelit bath, which in the end becomes the scene of her suicide (Figure 15). ${ }^{28}$ In the end, though, there is no "real" reason for Lady Macbeth to read Macbeth's letter in a bathtub; there is, in fact, no "real" bathtub. The tub in Sleep No More was quite solid and the surrounding floor slippery with fake blood, as I discovered on my one visit to that show. The tub in the Melbourne film has or had a material existence, although as viewers we experience only its filmic simulacrum. But the Shakespeare in Bits bathtub is at best just a pattern of pixels generated by some computer program we can never experience directly. 


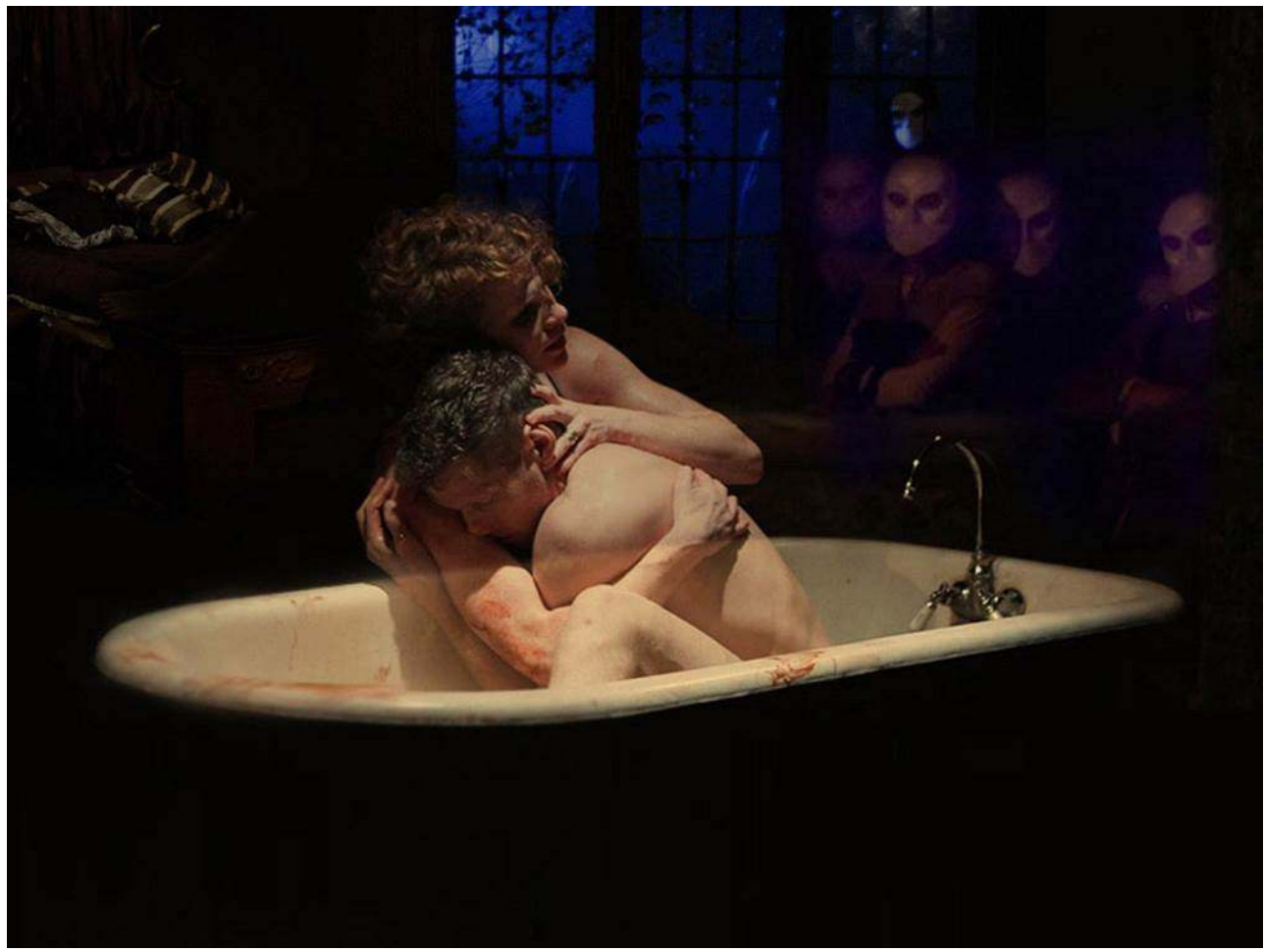

Figure 14: Lady Macbeth and Macbeth in the bath, Sleep No More.

Promotional image from the official Sleep No More website, screen grab. URL: http:// www.sleepnomore.com/images/room1-bg2.jpg

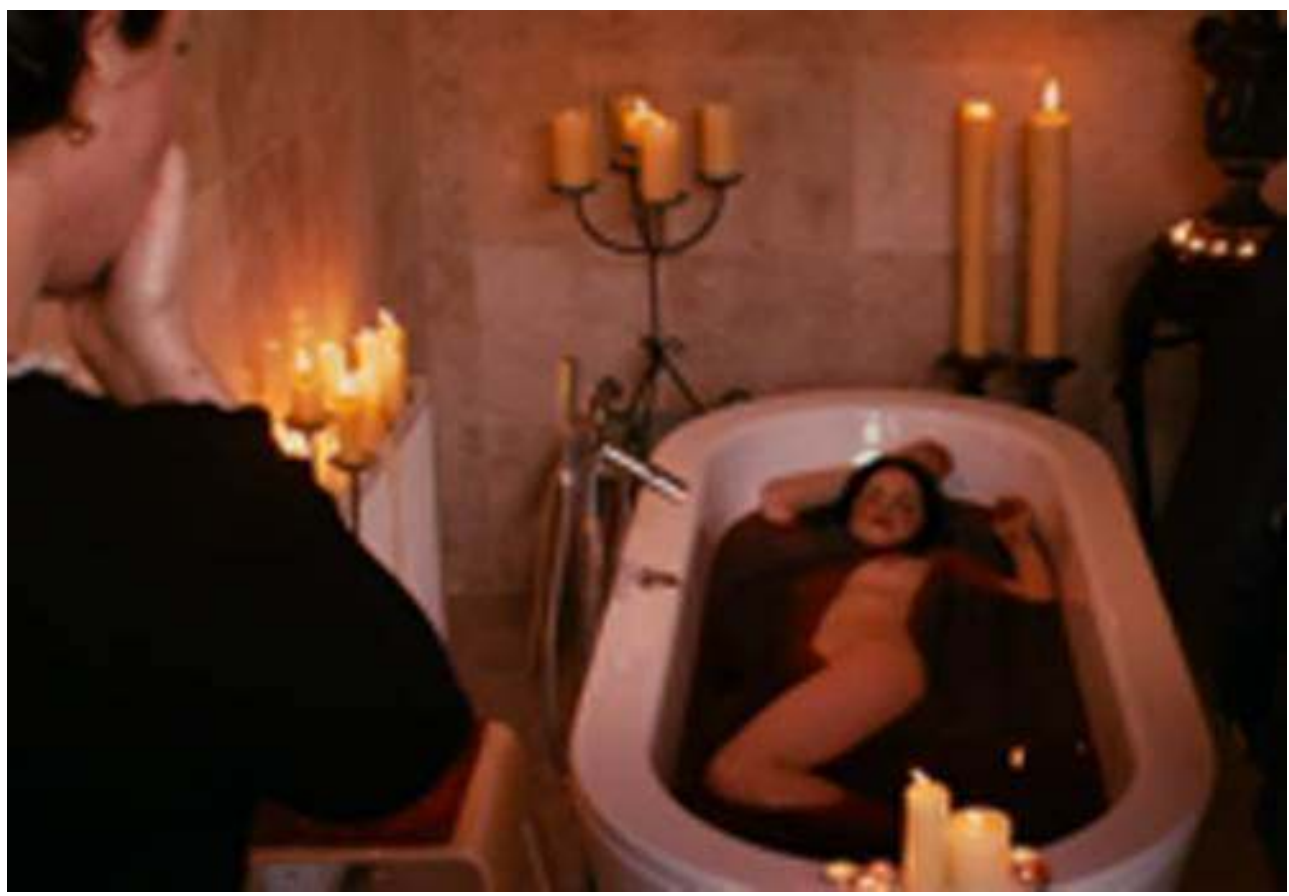

Figure 15: Victoria Hill as Lady Macbeth in Macbeth, dir. Geoffrey Wright, Mushroom Pictures. SCREENgRAB (MADMAN ENTERTAINMENT, DVD 2006). 
Yet all three tubs, as Bogost would say, are equally objects or units participating in a common system that comes into and fades out of existence in relation to other systems. So too for the three Lady Macbeths, at once embodied and disembodied, both cool data and warm affect. While allusions to other productions, either live or fictive, is common practice among Shakespeare adaptors, looking at this effect through the lens of alien phenomenology expands significantly the set of objects with potential agency. A pixelated tub exists on the same terms as the most of solid objects of film sets or immersive theater experiences, its existence and agency equal to that of the Manhattan building in which Sleep No More is set and to the intentions of Geoffrey Wright as filmmaker.

\section{Conclusion}

I think it worthwhile to pursue the alien phenomenology of Lady Macbeth in the bath precisely because the company behind Shakespeare in Bits, like many apps, promotes its product as offering unmediated and thus relatively unproblematic access to meaning in Shakespeare: the company website reads, "The combination of text, fully animated reenactment and audio soundtrack helps you decode Shakespeare's prose and facilitates learners of varying abilities and learning styles." There are similar misconceptions about the transparency and "relatability" of other apps, of easily searchable digital texts, and certainly, of YouTube's offerings in the Shakespeare sector. It is useful, I think, to meditate on the mysterious, secretive, and even self-serving objects lurking beneath the polished interfaces of digitized texts and on the hidden algorithm that steers YouTube. Instructive, as well, is the placement of the virtual Lady Macbeth, with her brown hair and the sprinkle of freckles across her nose, in the company of Fiona Shaw's voice, the specular image of Victoria Hill's body (from the Wright Macbeth), and rotating actresses in New York's Sleep No More, whose performances persist only in visitors' memories - and beyond that, in our alien phenomenology, to the conglomeration of real and virtual bathtubs in whose company these "women" find themselves. This is a useful exercise in alien phenomenology, the beginning of a conversation around the implicit question posed by the subtitle of Ian Bogost's Alien Phenomenology: "What is it like to be a (Shakespearean) thing?"

\section{NOTES}

1. For a coherent sample of recent Hamlet parodies, see, for instance, "Hamlet Wrecking Ball Parody," YouTube, 16 December 2013, https://www.youtube.com/watch?v=snOT715pLuk [accessed 9 October 2016]; “Wrecking Ball - Ophelia (Hamlet) Version,” YouTube, 14 January 2015, https://www.youtube.com/watch?v=GQvj84SWh5g [accessed 9 October 2016]; and "Wrecking Ball Parody - The Tragic Tale of Hamlet, Prince of Denmark," 6 October 2013, https:// www.youtube.com/watch?v=XhTsT3g50oQ [accessed 9 October 2016]. 
2. Ian Bogost, Alien Phenomenology: Or, What It's Like to Be a Thing, Minneapolis, University of Minnesota Press, 2012, Kindle. The terms "unit, "system," and "configuration" are introduced at loc. 444. Bogost's understanding of phenomenology as a method is particular to his work in the digital realm and is not to be confused with the perspectives of earlier writers on phenomenological relations.

3. Donna J. Haraway, Simians, Cyborgs, and Women: The Reinvention of Nature, London, Taylor and Francis, 1991; N. Katherine Hayles, How We Became Posthuman: Virtual Bodies in Cybernetics, Literature, and Informatics, Chicago, University of Chicago Press, 1999; Jane Bennett, Vibrant Matter: A Political Ecology of Things, Durham, Duke University Press, 2010.

4. Catherine M. Belsey, The Subject of Tragedy: Identity and Difference in Renaissance Drama, London, Methuen, 1995, p. 8.

5. Manuel de Landa, Intensive Science and Virtual Philosophy, London, Continuum, 2002.

6. Hayles, How We Became Posthuman, op. cit., p. 2-3.

7. Douglas Lanier, "Shakespearean Rhizomatics: Adaptation, Ethics, Value," in Shakespeare and the Ethics of Appropriation, ed. Alexa Huang and Elizabeth Rivlin, New York, Palgrave, 2014, 21-40, p. 28-29.

8. Ibid., p. 29.

9. Linda Hutcheon, A Theory of Adaptation, London, Routledge, 2006 writes that she prefers the "biological parallel" as a metaphor for adaptation as a process: "Evolving by cultural selection, traveling stories adapt to local cultures, just as populations of organisms adapt to local environments" (p. 177).

10. Bogost, Alien Phenomenology, op. cit., loc. 455-459. Here, Bogost is citing and discussing Bruno Latour, Reassembling the Social: An Introduction to Actor-Network Theory, Oxford, Oxford University Press, 2005, p. 46.

11. Bogost, Alien Phenomenology, op. cit, loc. 586-590.

12. Peter Holland, "Performing Shakespeare for the Web Community," in Shakespeare in Hollywood, Asia, and Cyberspace, ed. Alexa Huang and Charles S. Ross, West Lafayette, IN, Purdue University Press, 2009, 252-262, p. 255. At that time, Holland counted ten LEGO Macbeths; my search for "LEGO Macbeth" on YouTube on 19 May 2016 brought up 21,700 results.

13. See as well, Christy Desmet, "YouTube Shakespeare, Appropriation, and Rhetorics of Invention," in OuterSpeares: Shakespeare, Intermedia, and the Limits of Adaptation, ed. Daniel Fischlin, Toronto, University of Toronto Press, 53-72.

14. Ayanna Thompson, "Unmooring the Moor: Researching and Teaching on YouTube," Shakespeare Quarterly, 61, no. 3 (2010), 337-356; Valerie Fazel, "Researching YouTube Shakespeare: Literary Scholars and the Ethical Challenges of Social Media," Borrowers and Lenders: The Journal of Shakespeare and Appropriation, 10.1 (2016).

15. For more about the role of YouTube's algorithm in creativity and curation of videos on that site, see Christy Desmet, "YouTube Shakespeare, Appropriation, and Rhetorics of Invention," passim.

16. Kevin Slavin, "How Algorithms Shape Our World," TEDGlobal talk, YouTube, 21 July 2011, http://www.youtube.com/watch?v=TDaFwnOiKVE [accessed 21 April 2016].

17. Hugh Craig and Arthur F. Kinney, Shakespeare, Computers, and the Mystery of Authorship, Cambridge, Cambridge University Press, 2009, Kindle book, loc. 341.

18. Ibid., loc. 493.

19. Ibid. The way in which "Shakespeare" is mapped out in the scatter graphs and line graphs that illustrate Craig and Kinney's findings visualizes dramatically how the Author as Individual is reconceived by computational studies as a contingent configuration of single textual points in varied patterns. The reader should consult the figures in Craig and Kinney's book for examples. Some visual samples of Shakespeare-as-graph can also be seen in a readily accessible article by Hugh Craig, "Common-words frequencies, Shakespeare's style, and the Elegy by W.S.," Early 
Modern Literary Studies, 8, no. 1 (2002), 1-42, accessible online at http://purl.oclc.org/emls/08-1/ craistyl.htm [accessed 4 November 2016].

20. Shakespeare in Quarto, British Library, http://www.bl.uk/treasures/shakespeare/ quartos.html; Shakespeare Quartos Archive, http://www.quartos.org [accessed 4 November 2016].

21. William H. Sherman, Used Books: Marking Readers in Renaissance England, Philadelphia, University of Pennsylvania Press, 2008. The allusion to the potential of textual forensics here is based on a plenary panel at the 2016 Shakespeare Association of American meeting in New Orleans (23-26 March 2016). The panel, entitled "Shakespearean Forensics," included papers by Joshua Calhoun, Christina Warriner, Matthew Collins, and Michael Witmore.

22. See Christy Desmet, "The Shakespeare Quartos Archive," Shakespeare International Yearbook, 14: Special Section, Digital Shakespeares, ed. Brett D. Hirsch and Hugh Craig, Farnham, England, Ashgate, 2014, 143-154. This example is discussed on p. 151-152.

23. Laurie E. Osborne, "Clip Art: Theorizing the Shakespearean Film Clip," Shakespeare Quarterly, 53, no. 2 (2002), 227-240.

24. Jennifer L. Ailles, “'Is There an App for That?': Mobile Shakespeare on the Phone and in the Cloud," in Outerspeares: Shakespeare, Intermedia, and the Limits of Adaptation, ed. Daniel Fischlin, Toronto, University of Toronto Press, 2014, 75-112, p. 79.

25. Macbeth, Shakespeare in Bits, app for iPad, available at: https:// siblive.shakespeareinbits.com/siblive2/ [accessed 4 November 2016]. The company offers a twominute demo of Macbeth - the very beginning of the play - on its website.

26. Macbeth, Naxos Audio Books, http://www.naxosaudiobooks.com/316212.htm [accessed 4 November 2016].

27. Macbeth, dir. Roman Polanski, perf. John Finch, Francesca Annis, UK, Playboy Productions, 1971.

28. Sleep No More, immersive theater experience, Punchdrunk, New York, 2011-2016; Macbeth, dir. Geoffrey Wright, perf. Sam Worthington, Victoria Hill, Australia, Film Victoria, 2006.

\section{ABSTRACTS}

Shakespeareans have begun to study the bard in New Media, and a smaller group studies Shakespearean texts from the perspective of Digital Humanities research. However, these disciplinary divisions, with their varying theoretical perspectives, prevent us from seeing useful commonalities between these two domains of digital Shakespeare. This essay seeks to begin the conversation of examining digital shakespeare as a general category under the theoretical umbrella of Ian Bogost's "alien phenomenology," which regards objects of all kinds - concrete and abstract, "real" and imaginary - as existing equally, or as having a comparable ontological status. The theory insists at once on the autonomy and integrity of objects or units and on the ubiquitous enfolding of systems, and therefore of relationships, both within and beyond objects. Bogost's principal metaphor for what he calls not merely a "flat ontology" but a "tiny ontology," is the black hole, which is at once an infinitely dense point and an enfolded form of an entire universe. Following alien phenomenology in examples from YouTube, the searchable Folger Digital Texts, the Shakespeare in Quarto Archive, and both the Luminary and Shakespeare in Bits apps, the essay suggests how both persons and texts are units or objects imbricated in a system, or even tangle, of relationships that make up digital Shakespeare's systems of meaning. The 
essay concludes by suggesting that the investigation of alien phenomenology in digital Shakespeare artifacts both counteracts erroneous assumptions about the transparency and "relatability" of applications dedicated to Shakespeare and stresses the importance of recognizing a wide range of agents at play in digital Shakespeare.

Les études sur la présence de Shakespeare dans les nouveaux médias commencent à se développer, ainsi que l'analyse de ses textes du point de vue de la recherche en Humanités Numériques. Ces deux domaines qui traitent de Shakespeare dans le monde numérique, bien que souvent séparés, ont pourtant des points communs, que cet article s'efforce de faire ressortir à partir de la notion de "phénoménologie des choses " (alien phenomenology) développée par Ian Bogost. Il s'agit de considérer tous les objets (concrets et abstraits, « réels » et imaginaires) sur le même plan d'existence, de leur attribuer le même statut ontologique en insistant à la fois sur l'autonomie et l'intégrité des objets ou unités et sur l'omniprésence de systèmes, et donc de relations, au-dedans et au-dehors des objets. La métaphore centrale de cette théorie, que son auteur qualifie d'" ontologie du minuscule», est celle du trou noir, point à la fois infiniment dense et forme condensée d'un univers entier. Cet article analysera des exemples tirés de YouTube, des textes numérisés de la Folger Shakespeare Library, des archives Shakespeare in Quarto, et de deux applications, Luminary et Shakespeare in Bits, afin de montrer l'imbrication des objets et des personnes dans des réseaux enchevêtrés de relations qui constituent les systèmes d'interprétation $d u$ "Shakespeare numérique ». Grâce aux outils fournis par la théorie de Bogost, il est possible de réfuter des suppositions erronées concernant la transparence et l'accès direct à Shakespeare que prétendent donner certaines applications, tout en reconnaissant la grande variété d'acteurs impliqués dans le processus.

\section{INDEX}

Keywords: alien phenomenology, Bogost Ian, Deleuze Gilles, Folger Digital Texts, Guattari Félix, Hamlet parody, Luminary, rhizome, Shakespeare in Bits, Shakespeare in Quarto Archive, YouTube

Mots-clés: alien phenomenology, Bogost Ian, Deleuze Gilles, Folger Digital Texts, Guattari Félix, Hamlet, Luminary, parodie, rhizome, Shakespeare in Bits, Shakespeare in Quarto Archive, YouTube

\section{AUTHOR}

\section{CHRISTY DESMET}

University of Georgia 